\title{
Combining Learner Autonomy and Authentic Written Texts for the Acquisition of Business English Terminology
}

\author{
Nataša Gajšt
}

\begin{abstract}
Learning of Business English at tertiary level comprises the acquisition of specific linguistic and general competences together with the ability to learn the language autonomously. This paper presents the results of a study conducted with 123 first-year university-level students of Business English engaged in autonomous learning of business-related terminology by reading authentic business news over a period of five months. The data were collected over three academic years. The students were asked to rate the improvement of their linguistic competence, their attitudes towards autonomous learning and the use of authentic resources, and their improvement of the knowledge of business topics. The results showed that the students approved of reading authentic texts of their own choice as a way to develop their competences. The implication of this study is that autonomous learning should be encouraged and that authentic news articles are a good way to motivate students to learn Business English.
\end{abstract}

Key words: Learner autonomy, Authentic written texts, Linguistic competence, Business English terminology, Tertiary education

\section{Introduction}

At most European universities, study programmes have to comply with the Bologna-based system of education, which, among other things, places a significant emphasis on learner autonomy. Besides their in-class work, students are expected to do a substantial amount of independent study outside the classroom and teachers are to enable students to acquire such study skills which they will be able to utilise also when they leave the university. Autonomous learning at universities is therefore in line with the European Union's goals on the promotion of lifelong learning, which includes the learning of foreign languages, too (Bocanegra-Valle, 2008).

Apart from intended learning outcomes related to the course content (i.e. academic and professional goals such as the development of knowledge and understanding of a given subject by studying relevant up-to-date subjectrelated materials), course syllabi consistent with the Bologna principles address a number of cognitive and intellectual skills, transferable skills and practical skills that students should 
acquire and / or improve (e.g. developing greater independence of thought, using online resources and ICT, developing learning techniques and strategies for individual study, developing interest for lifelong learning).

The aim of this paper is to discuss the results of the assignments meant to encourage autonomous learning of Business English at the tertiary level in line with the above guidelines by focusing on the development of linguistic competences (in this case that means specialized terminology and reading skills), and on the acquisition of other subject-related skills and knowledge via reading authentic business and economics-related news articles in English as up-to-date sources of specialized terminology and business-related content.

As stated above, the ability to learn independently is a significant component of a learning process at the tertiary level and should therefore be encouraged in foreign language teaching and learning as well. Language learning autonomy includes a number of interrelated aspects. Benson (1997), for example, sees it as the capacity that enables learners to be more responsible for their language acquisition, which can be done in a number of ways, e.g. via 'authentic interaction with the target language and the control over the content of learning and control over resources' (p.33). Similarly, Sheerin (1997) states that autonomous students should, among other things, be able to decide on their own about the materials they will use for learning, to work unsupervised and to evaluate their progress (p. 57). In addition, the inclination of students towards autonomous learning is very important for its success and it is closely linked with their motivation to learn. Nation (2001) sees a combination of students' willingness to take the responsibility for and the control of their learning, their awareness of the types of approaches to learning a language and their skills and knowledge for autonomous learning as prerequisites for learner autonomy (pp. 394-395).

Of course, it goes without saying that the teachers also play an important role in the process of the development of students' language learning autonomy. According to Neupane (2010), 'learner autonomy does not free teachers from their responsibility. They should be more responsible to promote autonomy in learners' (p. 120). Littlewood (1997) sees the role of language teachers in the process of learner autonomy acquisition mainly as facilitators who help students develop motivation, confidence, knowledge and skills they require so that they can become more independent learners and more independent communicators (p.82). Successful autonomous language learning is therefore the result of students' study skills and their motivations to learn on the one hand, and the opportunities to be exposed to such way of learning as facilitated by teachers on the other.

Moving on to the very process of foreign language learning (including Business English), it can be said that it represents the acquisition and / or the

$66 \quad$ Journal of NELTA, Vol 18 No. 1-2, $\quad$ December 2013 
improvement of linguistic competences in that particular language (or its subfield) and also of competences needed for a successful outcome of learning, such as one's knowledge of the world, one's vocational and professional skills, one's attitudes towards and motivation for language learning as well as the development of one's study skills and heuristic skills (Council of Europe, 2001). The improvement of study skills is an important part of the autonomous learning process as students become better at using the available materials for independent learning. In addition, they raise the awareness of their own strengths and weaknesses as learners and become able to identify their own learning needs and goals (Council of Europe, pp. 101-108).

Yet, despite the fact that the development of general skills and competences is an important part of language learning, the main focus of language courses is still on the development of linguistic competences. In terms of Business English, this means also the acquisition of reading skills for academic and professional purposes, such as the ability to read business newspapers, business and economics texts, professional journals and textbooks, etc., and of specialized terminology related to various business and economics topics.

To learn Business English terminology and improve their reading skills at the same time, students can use a number of various non-authentic and authentic written texts. Although non-authentic materials have their advantages, they may become de-motivating for students if they include the topics that are outdated or not in line with their interests. Authentic texts, on the other hand, may prove more interesting and motivating as they present authentic, up-to-date and topical information. Littlewood (1997) also points out the use of authentic texts in language learning and emphasises their importance for learner autonomy on two levels:

First, on the affective level, learners who from the beginning have been exposed to authentic texts, rapidly develop confidence in the face of the target language. In particular, they quickly cease to worry that their comprehension may be incomplete, since they know that much can be achieved on the basis of partial comprehension. Secondly, on the psychological level, authentic texts accommodate the two-way relation between language learning and language use, encouraging the development of techniques of language learning that entail language use and techniques of language use that entail language learning (p. 231).

As we can deduct from the above quotation, the use of authentic texts should be encouraged in foreign language learning. Applying the above principles to Business English courses, we can claim that by reading authentic news articles on national and international business topics, students not only get the information about current events, thus broadening their knowledge of the business world but 
they acquire business and economicsrelated terminology. Also, by reading authentic texts, students become more confident as regards the use of Business English in their future careers.

\section{The present study}

In order to address the issues of the development of general and linguistic competences and the autonomous language learning at the tertiary level by using authentic written texts, the aim of this study was (1) to explore the students' perceptions of the improvement of their linguistic competence as a consequence of autonomous reading of business-related news, and (2) to investigate their views concerning the tasks in terms of the enhancement of learner autonomy and the enhancement of their declarative knowledge. Therefore, the study addressed the following research questions:

1.) How did autonomous reading assignments improve the students' English language knowledge, especially the knowledge of business and economicsrelated terminology?

2.) How did the students perceive the autonomous reading assignment as an activity for autonomous language learning via reading authentic materials in terms of the encouragement for self-study and the ability to use the available resources?

3.) How did the students rate their overall improvement of their declarative knowledge as the result of the assignments?

\section{Method}

\section{Participants}

Participants in this 3-year study were the $1^{\text {st }}$ year students of economics and business within the Bologna-based university programme 'Economics and Business Sciences' (i.e. BUN students) and within the Bologna-based professional higher education programme 'Business Administration' (i.e. BPHE students) at the University of Maribor, Slovenia. The students took our 'Business English 1' courses in the winter and summer semesters of the academic years 2010/2011, 2011/2012 and 2012/2013. The number of students in the university education programme was 74 (31 students in 2010/2011; 22 students in 2011/2012; 21 students in $2012 / 2013$ ) and the number of students in the professional higher education programme was 49 (16 students in 2010/2011; 16 students in 2011/2012; 17 students in 2012/2013). Based on the level of their secondary-school leaving exams, their expected level of the English knowledge was CEFR B1B2 level for BUN students (i.e. independent users of English) and A2B1 level for BPHE students (i.e. basic/ independent users of English). As the secondary-school English language programmes generally do not include English for specific purposes topics (but rather concentrate on more general topics and vocabulary in English), it was expected that a vast majority of students had almost no prior exposure to business and economics-related terminology. Also, it was presumed that they had a very limited knowledge of business and economics topics as they were only beginning with their business studies. 
Task design and task implementation - 'Reading logs'

The aims of the assignment, i.e. 'reading $\log s^{\prime}$, were for the students to take responsibility of their own learning of business and economics-related terminology by reading short business news articles from various resources of their own choice and their own interest in order to improve their reading skills in English and to learn business terminology. Besides that, the aim was also to help students use the available resources on the Internet in order to find and learn about up-to-date news related to national and international economic and business issues. The assignment presented only one part of our students' obligations within the courses, others being in-class tasks, weekly homework assignments, oral presentations of business topics and an end-of year written exam.

Before the students began with their 'reading logs' assignments and therefore the autonomous learning of business English terminology by reading authentic business news, they received written and oral instructions regarding the purpose and the implementation of the assignment. They were also given the reasons why they had to do these activities (i.e. to increase their autonomy and responsibility as learners of Business English and to expand their knowledge of business and economics-related topics). Apart from that, one such type of assignment was done in class for them to become well acquainted with the task procedure.
To carry out the tasks, the students had to complete the 'reading log' worksheets, in which they had to provide the following information about each business-related news article: the title, the source and the date of publication, personal opinion concerning the contents of the news (i.e. any interesting/new/surprising facts), and 5 business-related English words/ phrases (and their short definitions in English) they had found in the articles. The 'reading logs' worksheets had to be submitted at the end of each month in the period between November and March of each academic year. Each month, the students had to read 2 current business/economics-related news articles found in any daily newspaper written in English. The only prerequisite was that students had to choose each news item from a different periodical. The average length of each text had to be at about 300 words in the first three months and about 500 words in the last two months.

\section{Data collection}

The data for this study was collected at the end of the assignment in March every academic year via a 12-item questionnaire which was designed to elicit students' perception regarding their improvement of their linguistic competence and to assess the effectiveness of the assignment for autonomous learning of Business English. The students rated each statement on a 5-point Likert scale ( $1=$ 'I strongly disagree', 2 = 'I mildly disagree', 3 = 'Undecided'; 4 = 'I mildly agree'; 5 = 'I strongly agree'). Software SPSS 20 was used to analyse the responses. 


\section{Results}

Due to a relatively small sample size and a small number of items in the questionnaire, an internal consistency reliability of the questionnaire was first performed by the Cronbach Alpha coefficient. In both cases, the coefficients exceeded .7, which means that the questionnaire was reliable. Before carrying out statistical analyses to answer our research questions, ANOVAs were also run to establish whether there were any statistically significant differences between the students' responses in the three academic years for both groups of students because of a small number of responses per group in each academic year. Since the results showed no such differences, the answers of BUN students were combined into a single group and the answers of $\mathrm{BPHE}$ students were also combined into one group.

\section{Research question 1}

The first research question investigated the effects of the assignment (i.e. 'reading logs') on the improvement of the students' linguistic competence, and, more particularly, the knowledge of business and economics-related terminology. To answer this research question, the students had to rate the following statements:

'Lexical competence and overall linguistic knowledge' statements

S1: I had problems with understanding the texts because of the unknown businessrelated terminology.

S2: I found it difficult to extract professional terminology from the articles.

S3: I believe that reading logs helped me improve my knowledge of business/ economics related terminology.

S4: I believe that after completing all the tasks my overall knowledge of English has improved.

S5: After doing all the tasks (logs 1 to 5), it is easier for me to understand most business related news.

The first three statements focused on the students' knowledge and the acquisition of business/economicsrelated terminology while the last two addressed the overall improvement of their linguistic knowledge as a result of completing the assignments. The results for this set of statements are provided in Table 1.

Table 1:Mean scores for 'lexical competence and overall linguistic knowledge' statements

\begin{tabular}{|c|c|c|c|c|c|c|c|c|c|c|}
\hline & \multicolumn{2}{|c|}{ S1 } & \multicolumn{2}{|c|}{ S2 } & \multicolumn{2}{|c|}{ S3 } & \multicolumn{2}{|c|}{ S4 } & \multicolumn{2}{|c|}{ S5 } \\
\hline & M & SD & M & SD & M & SD & M & SD & M & SD \\
\hline BUN (N=74) & 2.86 & 1.127 & 2.80 & 1.098 & 3.69 & .757 & 3.43 & 1.061 & 3.45 & .894 \\
\hline BPHE $(\mathrm{N}=49)$ & 3.57 & 1.021 & 2.96 & 1.224 & 3.53 & .868 & 3.67 & .899 & 3.33 & .826 \\
\hline
\end{tabular}


As regards the statements concerning the students' lexical competence, it was established that BPHE students had more problems with understanding the articles because of the unknown terminology than BUN students. However, the mean scores for statement S4 showed that BPHE students thought that their overall knowledge of the English language had improved to a higher degree than was the case with BUN students.

Apart from the mean scores for these statements, we were also interested in establishing whether there were any correlations between these research items. The statistical correlation analysis (Pearson coefficient) showed the presence of a number of significant positive correlations for both groups of students. That is, in both groups the students who had problems with understanding the contents of the texts (S1) also had difficulties with finding business / economics-related terminology in the texts (S2). Besides that, the students who perceived the improvement of their knowledge of business / economics-related terminology (S3) also claimed that not only their ability to understand business-related news had improved (S5) but that their overall knowledge of English had improved over the course of the assignment as well (S4). The results also showed one negative correlation that occurred in the BPHE group's responses only. That is, those students who reported difficulties in understanding the texts due to the unknown specific terminology (S1) did not perceive their improvement of the knowledge of business/economics- related terminology (S3) as a result of the assignment.

\section{Research question 2}

The second research question dealt with the activity from the perspective of autonomous learning and the use of authentic resources. Since motivation is important in autonomous learning, we asked the students to state how motivated they were to carry out the tasks. Besides that, we were interested in establishing how the assignments improved the students' heuristic skills, particularly the skills of using the available sources for reading business news.

'Motivation' statements

S6: In general, I found the reading tasks interesting.

S7: I was glad that I had the freedom to choose the articles I found interesting.

S8: Reading tasks (logs) have encouraged me to read business news on my own.

The results in Table 2 display the mean scores for the 'motivation statements' responses.

\section{Table 2: Mean scores for 'motivation' statements}

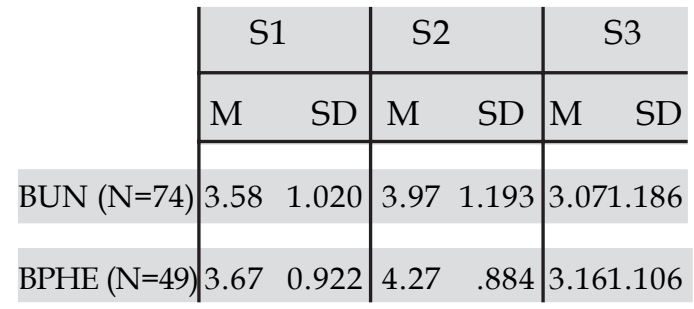

Table 2 shows that the students in both groups assessed the freedom to choose their own reading material as the highest motivating factor in completing 
the assignment. On the other hand, the average scores concerning the task being interesting and being the motivator to continue reading business news on their own received lower average scores. As with the statements under research question 1, we also performed the correlation analysis to see if there existed any correlations between these items. The analysis showed that there existed significant positive correlation in the BUN group between the students' perception of the tasks as being interesting (S6) and their freedom to choose the reading material on their own (S7). Concerning the BPHE group, a positive correlation between the students' perception of the tasks as being interesting (S6) and their motivation to continue reading the business news on their own (S8) was established. Nevertheless, this correlation proved to be a rather weak one.

\section{'Heuristic skills and learner autonomy' statements}

S9: The fact that I had to choose the reading material on my own was a problem for me.

S10: After completing the assignments, I can now better use the resources for reading business news (different newspapers, websites, etc.) for autonomous learning of professional terminology than at the beginning.

S11: In general, I would assess reading tasks (logs) as useful for autonomous learning of English.

The results in Table 3 display the mean scores for the 'heuristic skills and learner autonomy' responses.
Table 3: Mean scores for 'heuristic skills and learner autonomy' statements

\begin{tabular}{c|cc|cc|cc}
\multirow{1}{*}{} & \multicolumn{2}{|c|}{ S9 } & \multicolumn{2}{c|}{ S10 } & \multicolumn{2}{c}{ S11 } \\
\cline { 2 - 7 } & $\mathrm{M}$ & $\mathrm{SD}$ & $\mathrm{M}$ & $\mathrm{SD}$ & $\mathrm{M}$ & $\mathrm{SD}$ \\
\cline { 2 - 4 }$(\mathrm{N}=74)$ & 2.62 & 1.411 & 3.50 & .848 & 4.09 & .797 \\
BPHE (N=49) & 2.63 & 1.318 & 3.51 & .845 & 4.18 & .858
\end{tabular}

The mean scores in Table 3 regarding the students' heuristic skills show that the students from both groups did not have any major problems selecting their own reading material. Similarly, both groups of students perceived that their ability to find relevant resources for reading business news had somewhat increased. As regards the students' perceptions of the usefulness of the task for autonomous learning of English, the mean scores in both groups were more than 4 .

Since autonomous learning of foreign languages and the motivation to learn a language are interrelated, a correlation analysis was performed to establish if this was also perceived by the students in the research. The results of the analysis showed that those students who considered the reading tasks as useful for self-directed learning (S11) also perceived them as interesting (S6), and they were also motivated by the fact that they had the ability to decide what to read independently (S7). The analysis also established a rather strong correlation between the students' assessment of the task as being useful and their willingness to read about current business topics on their own (S8). However, those students who

$72 \quad$ Journal of NELTA, Vol 18 No. 1-2, $\quad$ December 2013 
reported having difficulties in choosing the articles on their own (S9) were less happy also with the fact that they had been asked to select the texts based on their personal preferences (S7).

\section{Research question 3}

The final research question in this study addressed the overall improvement of students' declarative knowledge, more specifically, the knowledge of business and economics-related topics. The students were asked to rate the following 'declarative knowledge' statement:

S12: Reading tasks (logs) have helped me broaden my knowledge of current business and economics topics.

The mean scores for this statement were as presented in Table 4 .

Table 4: 'Declarative knowledge' statement

\begin{tabular}{lcc} 
& \multicolumn{2}{c}{$\mathrm{S} 12$} \\
\cline { 2 - 3 } & $\mathrm{M}$ & $\mathrm{SD}$ \\
$\mathrm{BUN}(\mathrm{N}=74)$ & 3.78 & .832 \\
$\mathrm{BPHE}(\mathrm{N}=49)$ & 3.53 & 1.209
\end{tabular}

We see that both groups of the students agreed that these tasks increased their knowledge of current business and economics topics with the BUN group having a higher mean score. As the process of learning a foreign language (be it autonomous or not) is interrelated with the acquisition of declarative knowledge, we sought also to establish whether our students' answers reflected this interrelatedness. As regards both groups of the students, the analysis showed that those students who perceived the broadening of their knowledge of current business and economics topics as a result of the assignment (S12) also assessed that their overall knowledge of English improved (S4) and that they could understand most business news more easily than at the beginning of the tasks (S5). Also, the students who gave positive responses to S12 were also more likely to read about business topics outside the framework of the assignment (S8). Apart from that, they improved their skills for finding and using the available resources for learning business terminology (S10) and perceived the concept of reading logs as useful for selfdirected study of Business English (S11). In all these cases, the correlations were stronger in the BPHE group with the strongest one being between the business topics knowledge expansion and the students' readiness to read the news on their own.

\section{Discussion}

This study was motivated by the requirements of the tertiary education in Slovenia based on the Bologna principles, which require the students to do a lot of independent study within the programme courses. It was further motivated by the EU guidelines on lifelong education and, of course, by the objectives and the intended learning outcomes as defined in the course 
syllabus of 'Business English 1' courses, i.e. the introduction of business and economics-related terminology.

Therefore, the first research question addressed the improvement of business and economics-related terminology. The average scores which showed that the students enrolled in the professional higher education programme had more problems in understanding the articles can be a result of the fact that their existing level of English language knowledge was lower than was the case with the university programme students. On the other hand, their perceived improvement of the overall knowledge of English was higher than that of the university programme students. The results lead to the conclusion that the assignment was more beneficial for the students with the lower level of English language knowledge. The correlations that existed between the statements concerning lexical competence of students also revealed that those students who had problems understanding the contents of the news due to unknown business and economics-related terminology also had more problems in extracting this terminology from the articles. Nevertheless, the students who believed that the tasks helped them improve their knowledge of business and economicsrelated terminology also perceived that their ability to understand business news articles had increased. Based on that, the outcome of the activity in terms of the students' linguistic competence could be defined as successful.
Considering the second research question, which addressed the issues related to the autonomous learning of business English terminology in terms of the students' motivation to learn and their heuristic skills, the results of the study indicate that the freedom to choose their own reading material proved to be the most important motivating factor for the students and was actually what made the assignment interesting to them. This would also indicate that the students are more likely to read in a foreign language if and when they have the opportunity to choose the contents of their own liking and personal preferences, which is in turn important when learning the language they will need in their future business careers. In this way they became responsible for their own learning. However, it was slightly disappointing that the tasks did not encourage the students to read on their own outside the framework of this course assignment as much as we might have liked. This research question also dealt with the students' autonomy as learners of business English and their ability to search for the relevant information in the available resources to do so. The fact that most students did not experience a lot of problems when selecting their articles was positive since it showed their ability to select relevant reading material on their own.

In the final research question the effect of the assignment on the improvement of the students' knowledge of business topics was examined. Again, the task has proven useful as students perceived

$74 \quad$ Journal of NELTA, Vol 18 No. 1-2, December 2013 
that by doing this assignment, they had broadened their knowledge of current business and economics topics.

Overall, the results of this study thus show that the students approved of reading authentic texts for the improvement of both their linguistic competence and their knowledge of business topics with the main motivating factor being the opportunity to select the reading materials on their own. In addition, since a lot of significant correlations existed among the students' responses, the study has pointed out the interrelatedness of language learning, learning about the world, the usefulness of authentic texts and learner autonomy.

\section{Conclusions and pedagogical implications}

This study produced some useful findings for future work on learner autonomy and the use of authentic reading materials in the context of business English courses at a tertiary level. Being a tool for the improvement of students' linguistic competence and general knowledge of the world of business, authentic newspaper articles on business topics offer a good entry to the world of business terminology and current national and international business affairs, both of which the students will have to know if they are to be successful in their professional careers.

The students' responses have shown us that the future realisation of tasks will have to be more adapted to the existing level of language knowledge of students in terms of the difficulty of reading materials for the university programme students. It would also seem appropriate that in the future, more time should be spent on encouraging students to read in English by emphasising even more on the benefits this would bring to them in terms of the success in their careers. Nevertheless, the students' perceptions in this study regarding the usefulness of the assignment for autonomous learning of Business English, which were relatively high, indicated that a task like the one presented in this research should continue to be part of our courses.

\section{About the authors}

Nataša Gajšt, MA (American Studies) is a lecturer in English at the Faculty of Economics and Business, the University of Maribor (Slovenia). Her professional interests lie in vocabulary acquisition research, corpus linguistics, ESP lexicography and BE materials design. The author can be reached at natasa.gajst@uni-mb.si.

\section{References list}

Benson, P. (1997). The philosophy and politics of learner autonomy. In P. Benson \& P. Voller (Eds.), Autonomy and independence in language learning (pp. 18-34). London and New York: Longman.

Bocanegra-Valle, A. (2008). Learning to learn in ESP: Fostering lifelong learning in European higher education under Bologna requirements. In I. FortanetGomez \& C.A. Räisänen (Eds.), ESP in European Higher Education: Integrating 
Language and Content (pp. 213-232). Amsterdam: J. Benjamins.

Council of Europe (2001).Common European framework of reference for languages: Learning, teaching, assessment. Cambridge: Cambridge University Press.

Littlewood, W. (1997). Self-access: Why do we want it and what can it do? In P. Benson \& P. Voller (Eds.), Autonomy and Independence in Language Learning (pp. 79-91). London and New York: Longman.

Nation I. S. P. (2001). Learning vocabulary in another language. Cambridge: Cambridge University Press.

Neupane, M. (2010). Learner autonomy: concept and considerations. Journal of NELTA, 15 (1-2). Retrieved on 14th Aug. 2013 from http://nepjol.info/ index.php/NELTA/article/view/ $4617 / 3828$

Sheerin S. (1997). An exploration of the relationship between self-access and independent learning. In P. Benson \& P. Voller (Eds.), Autonomy and independence in language learning (pp. 54-65). London and New York: Longman. 